doi: http://dx.doi.org/10.5892/ruvrv.2010.81.1926

ARTIGO / ARTICLE

\title{
MELHORIA DA QUALIDADE DE SERVIÇO NA PRODUÇÃO DE CARVÃO NO SETOR DE CARBONIZAÇÃO: UM ESTUDO DE CASO
}

\author{
Ana Paula de Moura ${ }^{1}$ \\ João Eudes Campos ${ }^{2}$ \\ RESUMO \\ Sérgio Ricardo Magalhães ${ }^{3}$
}

Este artigo trata do levantamento de dados da produção de carvão vegetal pelo processo industrial com o intuito de verificar a possibilidade de mudança do perfil operacional do setor. Visou prestar um serviço de consultoria em uma Empresa denominada ALFA na busca de melhores resultados de produção, custos, qualidade do produto e alguns aspectos relacionados à sustentabilidade e meio ambiente $\mathrm{O}$ estudo apresentou soluções aos problemas relacionados à capacitação e melhor aproveitamento de seus colaboradores. Utilizou-se de uma metodologia de campo através de questionários e entrevistas realizadas com as pessoas envolvidas no processo. Evidenciou-se a necessidade da mudança do perfil da produção do carvão vegetal na Empresa ALFA. Estima-se que após as alterações propostas, os ganhos operacionais e econômicos serão significativos. Nos resultados pôde-se constatar uma necessidade do proprietário repensar o modelo de como era feito a carbonização da madeira em seus fornos. Assim, com a adequação da mão de obra, a produção de carvão vegetal resultou em ganhos diretos e indiretos.

Palavras chave: Carvão vegetal, qualidade, mão-de-obra.

\section{ABSTRACT}

This article deals with the data-collecting of the production of vegetal coal for the industrial process with intention to verify the possibility of change of the operational profile of the sector. It aimed at to give a service of consultoria in an Alpha called Company, in the search of better resulted of production, costs, product quality and some aspects related to the sustentabilidade and environment the study present solutions to the problems related to the qualification and better exploitation of its collaborators. One used of the metoldologia of field through questionnaires and interviews carried through with the involved people in the process. It was proven necessity of the change of the profile of the production of the vegetal coal in the Alpha Company. They is esteem that after the alterations proposals, the operational and economic profits will be significant. In the results a necessity of the proprietor could be evidenced to rethink the model of as the carbonization of the wood in its ovens was done. Thus, with the adequacy of man power the production of vegetal coal resulted in profits indirect right-handers and.

Keywords: Vegetal coal, quality, man power.

\footnotetext{
${ }^{1}$ e 2 Acadêmicos do curso de Administração da Universidade Vale do Rio Verde

${ }^{3}$ Professor do curso de Administração da Universidade Vale do Rio Verde
} 


\section{INTRODUÇÃO}

Sabe-se que uma característica importante da atividade florestal é a sua abrangência territorial e a alocação de mão de obra. O carvão vegetal representa hoje uma importante fonte energética no Brasil o que, de acordo com o Ministério de Minas e Energia, equivale a 12,9\% do total da energia primária consumida no país. Para garantir o constante abastecimento de carvão vegetal, torna-se fundamental a implementação do manejo florestal como fonte legal e sustentável de matéria-prima, e, por outro lado, o aperfeiçoamento das técnicas de produção e a capacitação dos recursos humanos.

Este artigo foi realizado a partir de pesquisa em uma unidade industrial produtora de carvão vegetal pelo processo de carbonização em fornos convencionais, na cidade de Pompéu, onde foi possível demonstrar que os aspectos produtivos do modelo adotado para a produção de carvão não estava atendendo aos requisitos básicos de produção e alocação de mão de obra.

$\mathrm{O}$ presente estudo tem como base as informações coletadas na empresa identificada como ALFA que por solicitação da própria empresa seus dados serão mantidos sob sigilo de forma a preservar a fonte de informação. Localizada na região do Alto São Francisco, a ALFA está próxima das áreas plantadas e dos seus clientes, facilitando assim o transporte de mão-de-obra e da produção. Hoje é formada por 39 (trinta e nove) funcionários. Atualmente, a ALFA presta serviços de carbonização para serem usados como termo redutor nos altos fornos das siderúrgicas, entre elas: Siderúrgica Alterosa, Pitangui Agro Florestal, na região de Pompéu MG.

O levantamento feito na Empresa ALFA detectou uma situação de redução da qualidade do nível de serviços desenvolvidos pela empresa, na produção de carvão vegetal para siderurgia. $\mathrm{O}$ principal objetivo foi identificar como é a distribuição das atividades dos funcionários na fabricação de carvão vegetal e apresentar soluções para uma melhor produtividade operacional.

Segundo a Sociedade Brasileira de Silvicultura (SBS, 2006), na classificação mundial de produção de carvão vegetal, o Brasil é um dos maiores produtores, sendo também um dos maiores consumidores, possivelmente, cabendolhe o título de único produtor de ferro-gusa a carvão vegetal do mundo.

A produção do carvão vegetal no Brasil responde por cerca de $1 / 3$ da produção mundial. Destes, em sua quase totalidade, para uso siderúrgico, mas ainda se produz, em sua grande maioria, como há um século, sem as preocupações básicas com o meio ambiente e com as condições de trabalho inadequadas.

O carvão é produzido de forma rudimentar na região de Pompéu e existe uma demanda crescente de carvão de alta qualidade para a indústria siderúrgica. A produção, transporte e comercialização do carvão vegetal empregam grande número de pessoas e opera em um sistema de mercado com interferência limitada das autoridades. Entretanto, apesar de requerer baixo investimento de capital permanecem disperso e pouco desenvolvido.

O nível de produtividade apurado pela Empresa ALFA não estava atingido os patamares exigidos pela siderúrgica contratante de seus serviços de produção de carvão, nem em quantidade nem em qualidade. Percebeu-se que esta baixa produtividade estava concentrada na distribuição das tarefas atribuídas aos funcionários e no número destes. A Empresa ALFA tem em seu processo produtivo de carvão vegetal, a utilização da força de trabalho homem/hora, o que representa grande parte de seus custos operacionais.

De forma a identificar e comprovar as principais causas deste nível de produtividade, aquém das exigidas pela siderúrgica contratante, este artigo fornecerá informações importantes à Empresa ALFA, propondo novas formas de distribuição das tarefas dos funcionários.

Face ao exposto, evidencia-se a necessidade da mudança do perfil da produção do carvão vegetal na Empresa ALFA e propor novas formas de distribuição das tarefas/funcionários da Empresa ALFA para reverter o processo final em uma ótima prestação de serviço.

\section{REVISÃO DE LITERATURA}

\subsection{Prestação de Serviço}

A prestação de serviços é entendida como a realização de trabalho oferecido ou contratado por terceiros (comunidade ou empresa), incluindo assessorias, consultorias e cooperação 
interinstitucional.

A prestação de serviços se caracteriza pela intangibilidade, inseparabilidade (produzido $\mathrm{e}$ utilizado ao mesmo tempo) e não resulta na posse de um bem, conforme descrito por Hoffman (2003).

A ALFA é uma empresa de prestação de serviços de carbonização, ou seja, a produção de carvão vegetal para ser usado como termo redutor nos altos fornos de siderúrgicas. Produz carvão vegetal a partir de florestas renováveis de eucalipto, focada na responsabilidade sócioambiental, possui uma atuação efetiva nas comunidades onde atua.

\subsection{Produção de Carvão, Pirólise ou Carbonização}

O carvão vegetal é proveniente da queima parcial da madeira. Na era primitiva, o homem utilizava pedaços de madeira em chamas para iluminar as cavernas ou aquecer-se. Possivelmente não tardou a perceber que, ao utilizar a madeira queimada, de aspecto preto e friável, esta não produzia chama e nem tanta fumaça, gerando calor de forma mais controlável que aquele produzido pela queima direta da madeira marcando a descoberta do carvão vegetal e seu uso como combustível. (JUVILLAR, 1980).

Segundo Sampaio (2001), o uso energético da biomassa vem sendo valorizado como forma alternativa ao uso de combustíveis fósseis, principalmente por ser uma fonte renovável. $\mathrm{Na}$ conversão energética da biomassa (gramíneas, bagaço de cana, casca de arroz, casca de côco, madeira, entre outras), faz-se uso dos processos termoquímicos. A biomassa é submetida à ação do calor até transformá-la em compostos mais simples.

Pirólise é o processo no qual um material é degradado termicamente numa atmosfera isenta de substâncias oxidantes. Da pirólise lenta da madeira formam-se dois tipos de produtos: sólido (carvão) e gases, sendo que parte destes se condensa formando alcatrão e líquido piro lenhoso.

A madeira é composta basicamente de carbono, oxigênio, água, hidrogênio, nitrogênio e sais minerais (OLIVEIRA et al, 1980), constituindo-se num dos componentes da biomassa de maior uso energético, por possuir características atraentes tais como produtividade, qualidade e massa específica adequada, além do seu baixo custo.

O processo da decomposição térmica pode resultar em destilação seca, quando realizado sob completa ausência de ar, recuperando-se todos os produtos oriundos da carbonização e obtendo-se o carbono fixo em forma de carvão vegetal. Quando a queima ocorre ao ar livre, a madeira se transforma em fumos, restando cinzas ou óxidos minerais.

\begin{tabular}{|c|c|}
\hline Produtos da Carbonização & \% Base Seca \\
\hline Carvão (80\% Carbono fixo) & $\mathbf{3 3 , 0}$ \\
Ácido pirolenhoso & $\mathbf{3 5 , 5}$ \\
(Ácido acético) & $(5,0)$ \\
(Metanol) & $(2,0)$ \\
(Alcatrão solúvel) & $(5,0)$ \\
(Água e outros) & $(23,5)$ \\
Alcatrão insolúvel & $\mathbf{6 , 5}$ \\
Gases não-condensáveis & $\mathbf{2 5 , 0}$ \\
(GNC) & $(0,16)$ \\
(Hidrogênio - 0,63\%) & $(8,5)$ \\
(CO - 34\%) & $(15,5)$ \\
(CO2 - 62 \%) & $(0,61)$ \\
(Metano - 2,43\%) & $(0,03)$ \\
(Etano - 0,13 \%) & $(0,20)$ \\
(Outros - 0,81 \%) & \\
\hline Total & $\mathbf{1 0 0 , 0}$ \\
\hline
\end{tabular}

QUADRO 1 - Itens e percentuais dos produtos resultantes da carbonização da madeira.

Fonte: Oliveira, (1980).

Segundo Rezende (2006), o processo de carbonização da madeira Eucaliptos ocorre em quatro fases:

- Fase I - Secagem: ocorre até $110^{\circ} \mathrm{C}$ quando apenas a umidade é liberada;

- Fase II - Torrefação: ocorre entre $110^{\circ} \mathrm{C}$ e $250^{\circ} \mathrm{C}$, sendo que na temperatura de $180^{\circ} \mathrm{C}$ tem início à liberação da água de constituição pela decomposição da celulose e hemicelulose e pouco peso é perdido até $250^{\circ} \mathrm{C}$. Forma-se o tiço ou madeira torrada;

- Fase III - Carbonização: ocorre entre $250^{\circ} \mathrm{C}$ e $350^{\circ} \mathrm{C}$ com a intensificação da 
decomposição da celulose e hemicelulose ocorre expressiva perda de peso, formandose gás, óleo e água. Ao atingir a temperatura de $350^{\circ} \mathrm{C}$ o carvão tem $75 \%$ de carbono fixo e se considera que a carbonização está praticamente pronta;

-Fase IV - Fixação: dos $350^{\circ} \mathrm{C}$ em diante ocorre redução gradual na liberação dos voláteis, principalmente gases combustíveis, continuando a fixação do carbono.

No caso da fabricação de carvão vegetal, aplica-se calor à madeira em ausência de oxigênio para desdobrar os seus complexos constituintes em gases (dióxido de carbono. monóxido de carbono. hidrogênio, entre outros), líquidos (alcatrões. ácido acético. álcool metílico, entre outros) e um resíduo sólido, que é o carvão vegetal. (REZENDE, 2006).

A operação de carbonização nos fornos de superfície consiste em encher os fomos, pelas portas com madeira seca ao ar e fechar o forno, deixando um orifício na parte superior, para fazer a ignição e uma série de outros orifícios ao nível do chão, para permitir a entrada do ar. Depois é feita a ignição pelo orifício da cúpula com tocos secos. A entrada de ar pelos orifícios da base é controlada aumentando-se ou diminuindo-se o seu tamanho, de modo que a combustão ocorra lentamente sem que o ar seja suficiente para queimar o carvão já formado.

O exato controle da tiragem é de vital importância e requer grande experiência. A operação deve ser vigiada dia e noite, até que a carbonização seja completa. Isso exige um período de vários dias, variável, conforme a umidade da madeira e o tamanho do forno.

\subsection{Fornos de Alvenaria}

O processo de produção de carvão vegetal predominante é constituído por fornos de alvenaria e argila, em muitos casos construídos com tijolos de barro fabricados no local onde serão montadas as carvoarias, o que torna seu custo muito baixo. (PINHEIRO et al, 2006). Quando são construídos em regiões de relevo acidentado são chamados de fornos de encosta ou barranco. Quando o terreno é plano são chamados fornos de superfície.

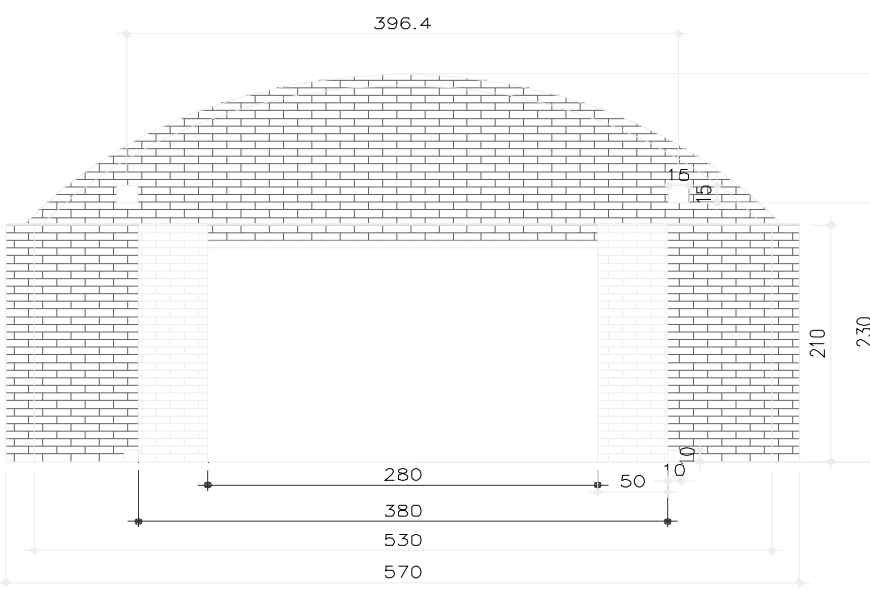

Figura 1: Desenho esquemático de um forno de superfície Fonte: Eudes, (2007).

Os fornos de alvenaria podem ser classificados pelo tamanho, medido pela capacidade efetiva de madeira enfornada. $\mathrm{Na}$ lista dos pequenos fornos existem os de encosta ou barranco e os fornos de superfície tipo "rabo quente", como nos mostra a Figura 1, colméia e $\mathrm{JG}^{\circledR}$, detalhados no Quadro 2.

Os fornos de encosta ou barranco alcançam

\begin{tabular}{|l|c|c|c|c}
\hline \multicolumn{1}{|c|}{ Fornos } & Encosta $(3 \mathrm{~m})$ & Rabo quente $(3 \mathrm{~m})$ & Colméia $(5 \mathrm{~m})$ & $\mathrm{JG}^{\circledR}(3 \mathrm{~m})$ \\
\hline Diâmetro (m) & $3,0-4,0$ & $2,9-3,8$ & $3,0-8,0$ & 3,0 \\
\hline Altura (m) & $2,5-2,8$ & 2,3 máx. & $3,2-5,0$ & 2,3 máx. \\
\hline Lenha enfornada & 20,0 st & 8,0 st & $5,0-200,0 \mathrm{t}$ & 14,0 st \\
\hline $\begin{array}{l}\text { Carvão/mês (MDC } \\
\text { metros de carvao) }\end{array}$ & 24,0 & $16,0-20,0$ & $50,0-60,0$ & 22 \\
\hline Ciclo (dias) & $7-8$ & $5-7$ & $8-9$ & $5-6$ \\
\hline Vida útil (anos) & 3 & $2-3$ & $3-5$ & $2-3$ \\
\hline
\end{tabular}

QUADRO 2 - Característica dos fornos de alvenaria considerados pequenos Fonte: Pinheiro et al, (2006). 
medidas de diâmetro entre 3,0 e 4,0 m $(5,30)$ e altura entre 2,5 e $2,8 \mathrm{~m}(3,35)$, o que permite receber lenha acima de $2,0 \mathrm{~m}$. Sua capacidade produtiva é de 10 (26) metros de carvão (MDC), a partir de 20 (50) estéreos (st) de lenha enfornada. $\mathrm{O}$ resfriamento desses fornos é mais lento do que os fornos de superfície, conferindo aos mesmos um perfil térmico mais homogêneo que o observado naqueles. (PINHEIRO et al, 2006).

\subsection{Qualidade e Rendimento do Carvão}

Para fins siderúrgicos o carvão deve possuir um conjunto de propriedades, agrupadas em pacotes (estruturais, de permeabilidade, energia/redução, reatividade e resistividade). Estas características devem ser estáveis e homogêneas. (PINHEIRO et al., 2006).
1) Composição Química

2) Umidade

3) Densidade aparente e verdadeira

4) Tamanho da peça

5) Análise imediata

6) Resistência mecânica

7) Porosidade

8) Friabilidade

9) Poder calorífico

10) Rendimento gravimétrico

Fator importante na qualidade do carvão vegetal é a friabilidade, que compreende a propriedade que o carvão vegetal possui de gerar finos, quando sujeito a esforços resultantes de abrasão e queda durante manuseio e transporte, o que pode resultar em até $25 \%$ de perda de acordo

\begin{tabular}{|l|c|c|c|c|}
\multicolumn{1}{|c|}{ Item } & $\begin{array}{c}\text { Carvão } \\
\text { vegetal }\end{array}$ & $\begin{array}{c}\text { Carvão } \\
\text { desejável }\end{array}$ & $\begin{array}{c}\text { Coque } \\
\text { metalúrgico }\end{array}$ & Coque de petróleo \\
\hline Carbono fixo \% & $68-78$ & $74-77$ & $82-89$ & $88-92$ \\
\hline Material volátil \% & $30-20$ & $25-22$ & $1,6-2,5$ & $7,8-11,0$ \\
\hline Cinzas \% & $1,0-3,5$ & $1-1,5$ & $9,5-15,9$ & $0,1-0,5$ \\
\hline Álcalis \% & Alta & $<20 \%$ & Baixa & Baixa \\
\hline $\begin{array}{l}\text { Basicidade Cinzas } \\
\text { (C+M) / (S+A) }\end{array}$ & Básica & C+M>S+A & Ácida & Ácida \\
\hline Umidade \% & Jun/15 & 4 a 6 & 5/jul & --- \\
\hline
\end{tabular}

QUADRO 3- Comparativo dos valores de itens que compõem os principais tipos de carvão utilizados na siderurgia. Fonte: Sampaio, (2001).

Um bom carvão tem poder calorífico de 30 a $33 \mathrm{mil} \mathrm{kJ} / \mathrm{kg}$, material volátil menor que $30 \%$ e teor de cinzas de 1 a $3 \%$. No processo convencional de carbonização, os melhores rendimentos gravimétricos são da ordem de $38 \%$ com produção em até 8 dias. Para a celulose temos estequiometricamente um rendimento gravimétrico possível de aproximadamente 44,4\%. (PINHEIRO 2006).

Estima-se que na produção de um bom carvão, possa atingir um rendimento gravimétrico de 44 a $55 \%$ e de maneira geral 50 a $80 \%$. (MOK, 1992).

As propriedades do carvão vegetal dependem da qualidade da madeira que lhe deu origem, do equipamento e das condições operacionais da carbonização. Leva-se em conta: com o tipo de movimentação. (PINHEIRO, 2006).

\section{METODOLOGIA}

Embasado pela colocação feita por Yin (2001), de que os estudos de caso, em geral, representam estratégia preferida quando se colocam questões do tipo "como" e "por que", quando o pesquisador tem pouco controle sobre os eventos e quando o foco se encontra em fenômenos contemporâneos inseridos em algum contexto da vida real.

A presente pesquisa se apresenta como qualitativa "porque envolve análise do conteúdo e análise de discurso, buscando-se opiniões dos sujeitos da pesquisa" e é descritiva, porque tem "como objetivo primordial a descrição das 
características de determinada população ou fenômeno ou, então, o estabelecimento de relações entre variáveis". (GIL, 2002).

Para dar suporte à pesquisa foram utilizadas as seguintes fontes:

a) Fontes primárias.

b) Fontes bibliográficas secundárias.

Utilizou-se como instrumento para a realização desta pesquisa um questionário de avaliação de produção. Os questionários foram estruturados de forma que, ao serem respondidas as questões sobre produtividade, processos, equipe de trabalho, equipamentos e demais informações sobre a atividade de produção de carvão permitissem ser descritas e identificadas.

Após a realização da pesquisa, verificou-se que havia vários setores que deveria atuar, mas o local onde havia mais falhas, e com maior probabilidades de ganho, era na unidade produtora de carvão, onde são realizadas as cargas (enchimentos) dos fornos e a carbonização, onde foram feitas as primeiras intervenções para $o$ melhoramento.

Para a Empresa ALFA, os custos da produção de carvão, referem-se aos valores gastos especificamente na realização do serviço. Os custos com a mão de obra são diretamente relacionados com o trabalho humano em atividades de transformação do produto/serviço. A matéria-prima é fornecida pelo cliente, no caso a siderúrgica contratante, o que reduz os custos totais da operação. Sendo assim, no contrato para essa prestação de serviço de produção de carvão não há custo com a matéria-prima, no caso a madeira.

\section{RESULTADOS}

O carvão vegetal é uma commodity, e como tal, tem seu preço regulado pelo mercado. Este produto é matéria-prima para o ferro-gusa, ferroliga e silício metálico, que também são commodities. Ainda, o ferro-gusa serve de base para a produção de commodities como o aço e fundidos de ferro.

Sendo assim, o conhecimento e o controle dos custos de produção do carvão vegetal se tornam de fundamental importância e se constituem fatores da maior relevância na composição da margem de contribuição por ocasião da venda.

Para possibilitar a verificação do atendimento ao parâmetro de custeio ideal, dentro do processo produtivo da Empresa ALFA, de forma a se tornar economicamente viável, buscou-se fazer um cenário comparativo entre o sistema industrial de produção do carvão vegetal pelo processo de carbonização em um ambiente onde os recursos humanos foram dimensionados para melhor produtividade - processo proposto - e o sistema de produção do carvão vegetal como pesquisado e em operação - processo atual.

As atividades da Empresa ALFA concentramse na produção de carvão a partir do recebimento da madeira que é estocada e mantida em repouso para secagem e, em seguida, direcionada à carga dos fornos para produção de carvão vegetal (carbonização).

Na Empresa ALFA, as atividades de produção de carvão adotam o seguinte período de produção: de segunda a sexta, durante quatro semanas no mês ( 21 dias trabalhados). Neste período processa-se a carga de madeira e retirada do carvão de 06 fornos por dia, transportando deste talhão 300 st por dia para a carvoaria.

A linha de fornos da Empresa ALFA é composta por 60 fornos com capacidade produtiva média de $25 \mathrm{mdc}$, ocorre em cada forno duas cargas por mês, para identificar a real capacidade produtiva da linha de fornos tem-se:

\section{0 fornos $x 2$ cargas $x 25$ mdc $=3000 \mathrm{mdc}$}

Com a deficiência percebida no enchimento e na carbonização dos fornos, os volumes de produção alcançados eram entre 23 e 24 mdc de produtividade por forno, e também devido às falhas na carbonização, não conseguia duas corridas em cada forno durante o mês, consequentemente não era alcançada a cota de $3000 \mathrm{mdc} / \mathrm{mês}$. Resultados que eram obtidos:

60 fornos $x 2$ cargas $x 23$ mdc (forno)
$=2760 \mathrm{mdc}$ (mês)

Como resultado desta baixa produtividade, a Empresa ALFA não recebia o prêmio adicional pago de $\mathrm{R} \$ 4,00$ (quatro reais) por mdc produzido a mais.

Também foi constatado que o baixo nível de rendimento pode ser relacionado a outras causas menos impactantes, como: 


\begin{tabular}{l|l}
\hline Atividade & Número de funcionários \\
\hline Roçada & 2 funcionários \\
Corte e desdobra & 2 operadores de moto-serra \\
& 2 ajudantes \\
Transporte & 4 motoristas \\
Carga nos fornos & 8 ajudantes \\
Acompanhamento dos fornos & 6 forneiros \\
& 6 ajudantes \\
Retirada do carvão do forno & 2 carbonizadores \\
Encarregado de produção & 1 funcionário na limpeza da bateria \\
Transporte para a siderurgia & 1 operador de máquina \\
Limpeza do refeitório & 1 encarregados \\
\hline Total de mão-de-obra & 3 motoristas \\
\hline
\end{tabular}

Tabela 1- Demonstrativo da quantidade de trabalhadores necessária por atividade na produção de carvão em Talhão de 13,3 ha.

Fonte: Empresa Alfa.

1. Lenha verde: a lenha foi cortada só dez dias antes da queima, sendo que a recomendação é cortar pelo menos 70 dias antes, de forma a alcançar secagem natural;

2. Carbonização com excesso de ar: a presença de buracos na pilha de carvão permite entrada de ar em excesso durante a queima.

3. Capacidade do forno: os fornos não foram preenchidos até sua capacidade máxima ou o tempo de carga e descarga está muito elevado.

As soluções para a alteração do processo produtivo, afim de atingir as metas da contratante, foi que o período de produção seja de aproximadamente 14/15 dias, definida a utilização de 02 funcionários para efetuar a carga/descarga em cada forno. Como o ciclo se estende por até 15 dias, adotou-se a operação da seguinte forma:

$\checkmark 01$ dia para a etapa de carga e descarga do forno,

$\checkmark \quad 06$ a 08 dias para a carbonização e

$\checkmark \quad 05$ a 06 dias para o resfriamento.

Com a nova metodologia, a Empresa ALFA adotou em sua linha de 60 fornos, a força de trabalha composta de 45 funcionários. A proposta apresentada definiu as diretrizes de alocação dos funcionários/tarefas para melhorar a qualidade dos serviços prestados e consequente aumento da produtividade.

A Empresa ALFA adotou a relação de dois homens para a operação de carga de 01 forno, o que a acarretou no incremento de custos da ordem de $\mathrm{R} \$ 7,00$ (sete reais) a mais por unidade produtora, porém a produtividade por forno passou a ser de $27 \mathrm{mdc} /$ forno.

A Empresa ALFA tem em seu plantel 60 fornos, fazendo duas cargas (mês), totalizando 120 fornos (mês). Com a nova metodologia ao tornar a produtividade de $27 \mathrm{mdc} / \mathrm{forno}$, estes passaram a produzir $3.240 \mathrm{mdc} / \mathrm{mês}$, o que permitiu que a Empresa ALFA atingisse a meta e recebesse o prêmio por cumprimento da cota, conforme descrito abaixo:

$$
\begin{aligned}
& \text { 60 fornos } x 2 \text { cargas }(\text { mês })=120 \text { fornos }(\text { mês }) \\
& 120 \text { fornos }(\text { mês }) \times 27 \mathrm{mdc}(\text { forno })=3.240 \mathrm{mdc}(\text { mês }) \\
& \text { Prêmio }=R \$ 4,00 \times 3.240 \text { mdc. } \\
& \text { Prêmio }=R \$ 12.960,00 \text { total apurado. }
\end{aligned}
$$

Aumento de custo para esta produtividade $=$ 120 fornos (mês) $x \boldsymbol{R} \$ 7,00=R \$ 840,00$ (mês)

\section{Resultado final $=$}

$R \$ 12.960,00-R \$ 840,00=R \$ 12.120,00$ 


\section{CONSIDERAÇÕES FINAIS}

Finalizando as informações e dados coletados durante a pesquisa, bem como a observação do processo produtivo da Empresa ALFA, foram definidas propostas de alterações como a adequação do quadro de funcionários. Outro fator de melhoria na produção foi em qualidade final do produto. Possibilitou a obtenção de resultados também no processo de carbonização, pois, com a produção dos fornos em sua capacidade máxima, reduziu-se a emissão de poluentes na atmosfera e obteve-se um melhor rendimento gravimétrico.

Com base nos resultados do presente estudo pode-se concluir que a adequação do uso da mão de obra e a consequente alteração da força de trabalho, apresentaram:

$\checkmark$ Valores de densidade produtiva básica superiores, havendo diferença expressiva em relação ao volume produzido em períodos semelhantes;

$\checkmark$ Maior rendimento em carvão, por forno carregado, o que representou ganho de produtividade com o mesmo plantel de fornos;

$\checkmark$ Carvão vegetal mais denso, poder calorífico com valores mais constantes em função de melhor enchimento dos fornos, resultando em uma ótima carbonização.

Finalmente, pôde-se concluir que a adequação da mão de obra à produção de carvão vegetal por parte da Empresa ALFA resultou em ganhos diretos $\mathrm{e}$ indiretos, o que foi prontamente comprovado com a demonstração detalhada por estudos de ordem técnico-econômica ligados à produtividade, alocação de mão de obra e equipamentos.

\section{REFERÊNCIAS}

GIL, Antônio Carlos. Como elaborar projetos de pesquisa. 4. ed. São Paulo: 2002.

HOFFMAN, K. Douglas. Princípios de marketing de serviços: conceitos, estratégias e casos. São Paulo: Pioneira Thomson Learning, 2003.

IBGE. Boletim da diretoria de pesquisas, coordenação de agropecuária, produção da extração vegetal e da silvicultura. Rio de Janeiro: IBGE, 2003

JUVILLAR, Joaquim Burrel. Tecnologias da transformação da madeira em carvão vegetal Belo Horizonte: CETEC, 1980.

OLIVEIRA, J. B. de. Produção de carvão vegetal - aspectos técnicos. Belo Horizonte: CETEC, 1980.

PINHEIRO, P.C.C. A produção de carvão vegetal: teoria e prática. Belo Horizonte: CETEC, 1980.

REZENDE, Maria Emília. Produção de carvão vegetal - importância do conhecimento fundamental. Belo Horizonte: 2006.

SAMPAIO, Ronaldo Santos. Produção de metais com biomassa plantada. Belo Horizonte: LabMídia, 2001, pg. 164

SBS - Sociedade Brasileira de Silvicultura. Fatos e Números do Brasil Florestal 2005. Disponível em: <www.sbs.org.br>. Acesso em: 7 junho 2009.

YIN, Robert K. Estudo de caso: planejamento e métodos. 2 ed. Porto Alegre: Bookman, 2001. 